\title{
Eco-friendly Cotton Coloration Using Banana (Musa Sapientum) Waste: Optimization of Dyeing Temperature
}

\author{
Md. Reazuddin Repon ${ }^{1, *}$, Md. Abdullah Al Mamun ${ }^{1}$, M Tauhidul Islam ${ }^{1,2}$ \\ ${ }^{1}$ Department of Textile Engineering, Mawlana Bhashani Science and Technology University, Bangladesh \\ ${ }^{2}$ Institute of Radiation and Polymer Technology, Bangladesh Atomic Energy Commission, Bangladesh
}

Copyright $(2016$ by authors, all rights reserved. Authors agree that this article remains permanently open access under the terms of the Creative Commons Attribution License 4.0 International License

\begin{abstract}
Temperature has a promising role in textile coloration process. This study intends to optimize the dyeing temperature for sustainable coloration of cotton fabric employing banana waste. Natural dye retrieved from banana floral stem by roller squeezer machine. To explore the effect of temperature, samples were dyed for $60^{\circ} \mathrm{C}, 70^{\circ} \mathrm{C}, 80^{\circ} \mathrm{C}$, $90^{\circ} \mathrm{C}, 100^{\circ} \mathrm{C}$ and $110^{\circ} \mathrm{C}$ respectively by keeping constant time at 60 minutes. Effect of temperature variation on colorimetric appearance were expressed using CIE L ${ }^{*}{ }^{*} b^{*}$ color space in terms of color co-ordinates, color strength $(\mathrm{K} / \mathrm{S})$, brightness index $(\mathrm{BI})$ and degree of color levelness values. The dye fiber bonding stability was accessed via color fastness to wash, water, perspiration, rubbing and light. Except light fastness property almost color fastness value was 3-5 i.e. good to excellent. Best result of $\mathrm{K} / \mathrm{S}$, bright index $\%$ and color levelness value recorded $0.65,50.58$ and 0.069 respectively for $100^{\circ} \mathrm{C}$. Excellent color fastness properties also appeared for $100^{\circ} \mathrm{C}$. This reports prognosis an environmental begins approach for coloration of cotton fabric by deploying of banana plant waste.
\end{abstract}

Keywords Natural Dye, Eco-friendly Coloration, Color Fastness, Banana Waste Exploitation

\section{Introduction}

Chemical processing is irrevocable for textile coloration. During textile processing huge amount of various essential dyes and auxiliary chemicals are habitually consumed. So, in keeping with volume and composition, effluent of textile plants are most polluting amongst all industrial sectors [1, 2]. This huge amount of toxic and hazardous wastewater is finally discharge into the rivers, canals and water streams resulting in adverse effects on flora and agricultural land and thus presumed as one of the major sources for environmental pollution [3].

The specialists around the world are attempting to build up a cleaner innovation and ecologically supporting methods of cotton coloring for conforming to continuously requesting ecological regulation and to save water, energy and time [10]. Sustainable textile coloration is possible either by using green ingredients or zero discharge of wastewater $[4,5]$.

In this regards natural dyes are eco-friendly, safe, cheap, need no special care, uncommon and soothing shades, wonderful and rich in tones, act as health cure, have no disposal problems, non-carcinogenic, non-allergic, non-toxic, easily biodegradable, require simple dye house to apply on matrix and mild reactions conditions are involved in their extraction and application [6-8]. There are various potential sources such as plants, insects/animals, microbes, minerals and renewable bio resource products.

Among all other sources banana is most promising for ample availability. After citrus, banana is the second biggest created natural product which is contributing around $16 \%$ of the aggregate world organic product generation in 129 nations around the globe [9]. During performing research work it was presumed, in matured banana plant relative percentages of different parts assumed as 9\% floral stem, $41 \%$ outer part of pseudo-stem, $11 \%$ fruit, $6 \%$ peel, $3 \%$ peduncle, $14 \%$ underground parts and $16 \%$ leaf stalk and leaf. So it concluded, after harvesting of banana fruit almost $89 \%$ of banana plant is accounts as waste. This huge amount of banana waste has no remarkable exploitation.

Banana plant parts are engaging in textile arena such as table mat, stylish hand bag, eco-shopping bag, laminated fabric, yarn, saree, shirt, female dress, night dress, coaster etc. [10]. Moreover, banana plant parts also involved with mordanting [12], flame retardant finishing of cotton [13] and promising dye adsorbent of textile effluent [14]. Banana leaf [8] and pseudo stem sap mixed another natural dye [11] had used for cotton coloration. But till now no researcher had investigated banana floral stem sap for cotton coloration.

So, aim of this work is to quantify dyeing temperature for reasonable green coloration of cotton fabric and effective exploitation of bio-resource waste of banana plant.

\section{Experimental}




\subsection{Materials and Chemicals}

\subsubsection{Materials}

Commercially scoured-bleached $100 \%$ cotton knitted single jersey structure fabric having areal density of 175 grams per square meter was collected from "HI-FASHION COMPOSITE TEXTILES LTD”, Joydeppur, Gazipur, Bangladesh. Following table 1 depicts the color co-ordinates of the cotton knitted fabric that used for this investigation.

Table 1. Whiteness Index (WI), Brightness Index (BI) and Color coordinate value of commercially scoured-bleached cotton fabric

\begin{tabular}{|c|c|c|c|c|c|c|}
\hline $\mathbf{W I}$ & $\mathbf{B I}$ & $\mathbf{L}^{*}$ & $\mathbf{a}^{*}$ & $\mathbf{b}^{*}$ & $\mathbf{c}^{*}$ & $\mathbf{H}$ \\
\hline 68.38 & 94.19 & 93.68 & -0.30 & 3.67 & 3.68 & 94.74 \\
\hline
\end{tabular}

\subsubsection{Dyes \& Chemicals}

Banana floral Stem (Musa sapientum) was collected from Santosh, Tangail-1902, Bangladesh used as natural dye. ISO Standard Soap without optical brightener collected from James heals, England had used for removing the unfixed dye from colored sample surface.

\subsection{Methods}

\subsubsection{Dye extraction}

Banana (Musa sapientum) floral stem were separated from banana pseudo stem and washed. Fresh floral stem were cut into one meter pieces using cutlass and then sliced. Sap was extracted from sliced floral stem by roller squeezer machine. Sap mixture was filtrated by a nylon strainer. The sap solutions were stored in transparent plastic containers. Sap was kept in a cool place and was prevented from sun rays to avoid evaporation and possible reaction.

\subsubsection{Sampling}

Samples dyed at $60,70,80,90,100$ and $110^{\circ} \mathrm{C}$ were identified as A, B, C, D, E and F.

\subsubsection{Dyeing}

Dyeing had carried out according to exhaust method by Infra-red lab sample dyeing machine (XIAMEN RAPID, China) for $60,70,80,90,100$ and $110^{\circ} \mathrm{C}$ respectively at 60 minutes (Figure 1). Then the dye bath was cooled at $40^{\circ} \mathrm{C}$ and samples were washed at room temperature. Samples were squeezed and air dried in flat dryer machine (MESDAN, Italy).Then soaping was performed for removing unfixed dye form the fabric surface by $0.5 \mathrm{~g} / \mathrm{L}$ ISO standard soap at $80^{\circ} \mathrm{C}$ for 10 minutes. For both dyeing and soaping material to liquor ration had kept 1:20.

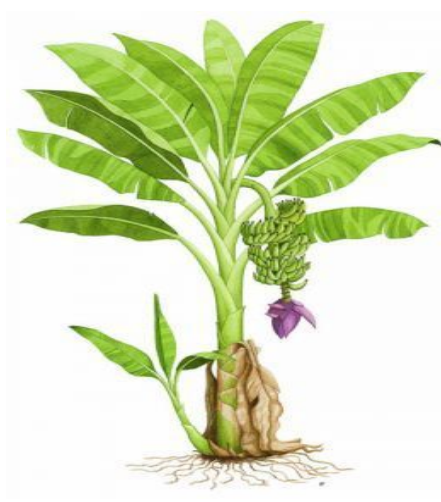

Banana Plant

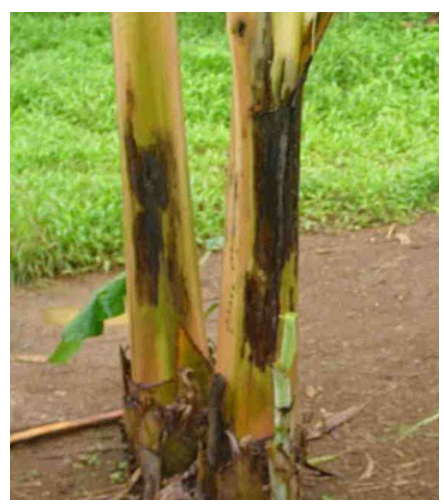

Pseudostem

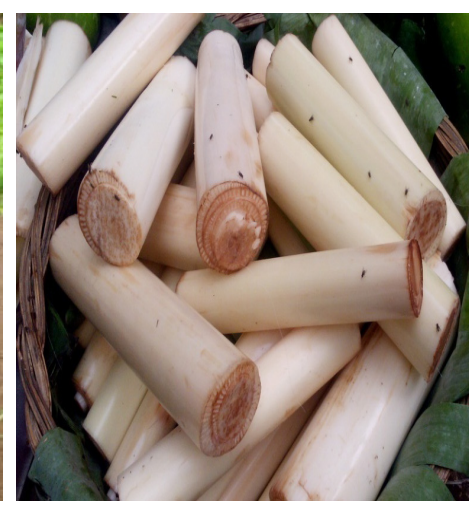

Floral stem

Figure 1. Different parts of banana plant

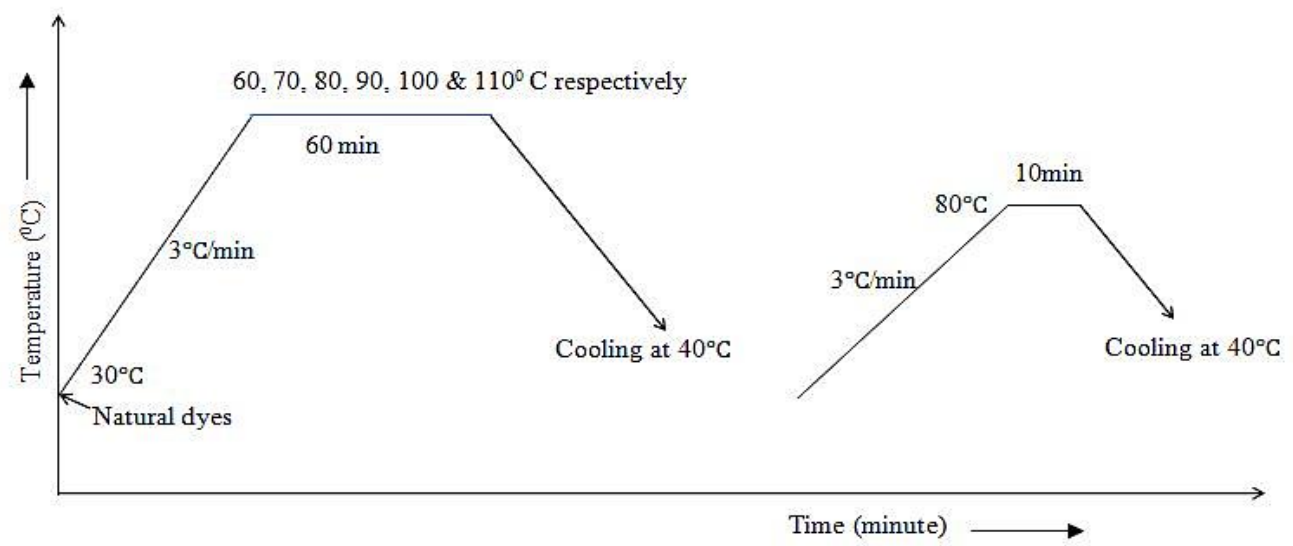

Figure 2. Dyeing Curve 


\subsubsection{Color Coordinates Dyed Fabric}

Based on the CIE Lab system the color coordinates of the dyed samples were determined via dual beam reflectance Data-color Spectroflash SF 650X (USA) keeping the setting: Illuminant D65, Medium area view, Specular included and CIE 1964 supple-mental standard observer (10 observer). Each sample was folded twice to give an opaque view with four plies and the color coordinates value was measured automatically.

\subsubsection{Determination of Degree of Color Levelness}

Data color spectrophotometer with specified setting, the degree of levelness of each dyed sample were measured considering the reading-1 as standard and other nines as sample batches. Data for each batch are analyzed with respect to color difference, $\Delta \mathrm{E}$ value. $\Delta \mathrm{E}$ is a single value that takes into account the differences between the $\mathrm{L}^{*}, \mathrm{a}^{*}$ and $b^{*}$ values of the sample and standard in the CIE L*a*b* color system. The Equation 1 was used to calculate the $\Delta \mathrm{E}$ value [15].

$$
\Delta \mathrm{E}=\sqrt{\left(\Delta \mathrm{L}^{*}\right)^{2}+\left(\Delta \mathrm{a}^{*}\right)^{2}+\left(\Delta \mathrm{b}^{*}\right)^{2}}
$$

Where, $\Delta \mathrm{L}^{*}=\mathrm{L}^{*}$ sample $-\mathrm{L}^{*}$ standard, $\Delta \mathrm{a}^{*}=\mathrm{a}^{*}$ sample - $\mathrm{a}^{*}$ standard, $\Delta \mathrm{b}^{*}=\mathrm{b}^{*}$ sample $-\mathrm{b}^{*}$ standard; standard refers to the reading-1 in dyed fabric, sample refers to other readings in the corresponding dyed fabric. The degree of levelness was described according to $\Delta \mathrm{E}$ values [16] as shown in Table 2.

Table 2. Suggested interpretation of $\Delta \mathrm{E}$ values

\begin{tabular}{|c|c|c|}
\hline$\Delta$ E values & $\begin{array}{c}\text { Visual appearance } \\
\text { of levelness }\end{array}$ & Extent of unlevelness \\
\hline$\leq 0.20$ & Excellent levelness & Unlevelness not detectable \\
\hline $0.21-0.50$ & Good levelness & $\begin{array}{c}\text { Unlevelness noticeable under } \\
\text { close examination }\end{array}$ \\
\hline $0.51-1.0$ & Poor levelness & Apparent unlevelness \\
\hline$>1.0$ & Bad levelness & Conspicuous unlevelness \\
\hline
\end{tabular}

\subsubsection{Determination of Color Strength}

The color strength $(\mathrm{K} / \mathrm{S})$ value of the dyed samples was measured by data color spectrophotometer based on KubelkaMunk theory which gives the relationship (Equation 2) between $\mathrm{K} / \mathrm{S}$ and $\mathrm{R}$ as mentioned below [17].

$$
\frac{\mathrm{K}}{\mathrm{S}}=\frac{(1-\mathrm{R})^{2}}{2 \mathrm{R}}
$$

Where, $\mathrm{R}$ is reflectance of an incident light from the dyed material, $\mathrm{K} \& \mathrm{~S}$ is absorption and scattering coefficient of the dyed fabric respectively.

\subsubsection{Determination of Brightness Index}

Brightness index was measured as per the standard (ISO-2470-1977) [18] method using following relationship (Equation 3) after measuring the reflectance value of the corresponding sample by Data color spectrophotometer according to specified setting only specular excluded was set. Each sample was folded twice to give an opaque view with four plies and the reflectance value was measured automatically.

Brightness index =

Refletance value of the substrate at $360 \mathrm{~nm}$

Reflectance value of white diffuser or white tile at $360 \mathrm{~nm}$

\subsubsection{Determination of Color Fastness}

Evaluating various color fastness properties of the selected dyed fabric standard methods was employed. Color fastness to wash, rubbing (dry and wet), light, water, perspiration, was accessed by using grey scale of color change and staining according to ISO 105-C06:2010 [19], ISO-105x12:1995 [20], EN ISO 105-E01:2013 [21], ISO 105-E04:2013 [22] and EN ISO 105-B02: 2013 [23] correspondingly.

\section{Result and Discussion}

\subsection{Color Co-ordinates Value of Dyed Samples}

Table 3 depicts the CIELAB color co-ordinates of dyed samples.

Table 3. Color co-ordinate value

\begin{tabular}{|c|c|c|c|c|c|}
\hline \multirow{2}{*}{$\begin{array}{c}\text { Sample } \\
\text { types }\end{array}$} & \multicolumn{5}{|c|}{ Color co-ordinates value } \\
\cline { 2 - 6 } & $\mathrm{L}^{*}$ & $\mathrm{a}^{*}$ & $\mathrm{~b}^{*}$ & $\mathrm{C}^{*}$ & $\mathrm{~h}^{\circ}$ \\
\hline $\mathrm{A}$ & 82.10 & 3.29 & 11.17 & 11.64 & 73.59 \\
\hline $\mathrm{B}$ & 82.20 & 3.42 & 11.17 & 11.68 & 72.98 \\
\hline $\mathrm{C}$ & 81.21 & 3.45 & 11.03 & 11.17 & 72.18 \\
\hline $\mathrm{D}$ & 82.82 & 3.06 & 10.56 & 10.99 & 73.83 \\
\hline $\mathrm{E}$ & 80.32 & 4.11 & 12.54 & 13.19 & 71.85 \\
\hline $\mathrm{F}$ & 80.75 & 3.97 & 12.04 & 12.68 & 71.75 \\
\hline
\end{tabular}

Regarding lightness $\left(\mathrm{L}^{*}\right)$, the samples orders were found as $\mathrm{D}>\mathrm{B}>\mathrm{A}>\mathrm{C}>\mathrm{F}>\mathrm{E}$. Minimum $\mathrm{L} * 80.32$ was yield for the sample $\mathrm{E}$ i.e. maximum darkness. Gradual increase of dyeing temperature has both positive and negative impact on color lightness. The sample A, B, C and F were $2.22 \%, 2.34 \%$, $1.11 \%$ and $0.54 \%$ lighter than E. Maximum lightness was observed for the sample D that was $3.11 \%$ more than E. Regarding redness $\left(\mathrm{a}^{*}\right)$ orders of samples were found $\mathrm{E}>\mathrm{F}>\mathrm{C}>\mathrm{B}>\mathrm{A}>\mathrm{D}$. Maximum redness were showed for the sample E. The samples A, B, C and F were $7.52 \%, 11.76 \%$, $12.75 \%$ and $29.72 \%$ redder than $\mathrm{D}$. Concerning yellowness $\left(b^{*}\right)$ orders of samples were found $E>F>A, B>C>D$. Among all $\mathrm{E}$ has maximum yellowness. The sample $\mathrm{C}, \mathrm{D}$ and $\mathrm{F}$ were $12.04 \%, 15.79 \%$ and $3.99 \%$ bluer than E. But A and B showed same yellowness. The orders color saturation $\left(\mathrm{c}^{*}\right)$ of samples were found to be $E>F>B>A>C>D$. The highest saturation was exhibited for $\mathrm{E}$ and lowest for $\mathrm{D}$ among all samples. Sample A, B, C and F were 11.75\%, 11.45\%, 15.32 and $3.87 \%$ low color saturation than E correspondingly. For hue angle $\left(\mathrm{h}^{\circ}\right)$ orders of samples were found $\mathrm{D}>\mathrm{A}>\mathrm{B}>\mathrm{C}>\mathrm{E}>\mathrm{F}$. Highest hue angle was showed for $\mathrm{D}$. The hue angle of sample A, B, C and E were $2.56 \%, 1.72 \%$, $0.60 \%$ and $0.14 \%$ higher than $\mathrm{F}$.

The dynamic equilibrium state of dyeing process may be 
attained rapidly by raising the temperature for enhance the degree of fibre swelling and the rate of diffusion of dye molecules [25]. But in case of 70 , and $90^{\circ} \mathrm{C}$ contradictory upshot looked probably due to chemical potential difference between dye-fiber molecule adsorption and desorption simultaneously taken place up to attain equilibrium [28].

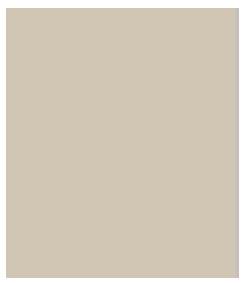

$60^{\circ} \mathrm{C}$

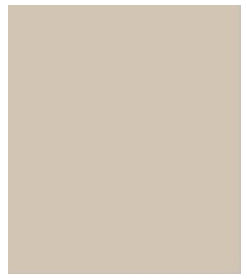

$90^{\circ} \mathrm{C}$

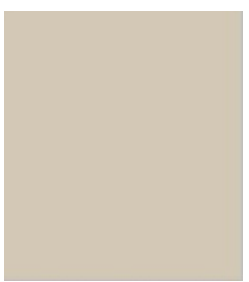

$70^{\circ} \mathrm{C}$

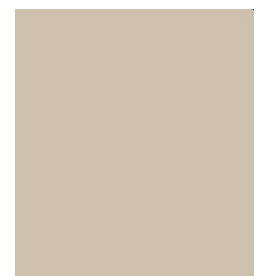

$100^{\circ} \mathrm{C}$

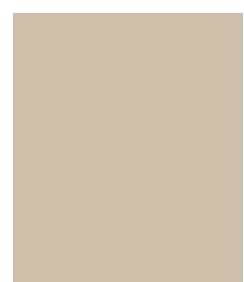

$\mathbf{8 0}^{\circ} \mathrm{C}$

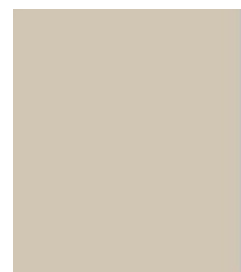

$110^{\circ} \mathrm{C}$
Figure 3. Photograph of dyed samples at various temperatures

\subsection{Degree of Color Levelness}

Table 4 express the effect if temperature variation on degree of color levelness value.
The temperature has both positive and negative effect on degree of color levelness (Table 4). The orders average color difference value of samples were found $\mathrm{A}>\mathrm{B}>\mathrm{D}>\mathrm{F}>\mathrm{C}>\mathrm{E}$. Lowest $\Delta \mathrm{E}$ value i.e. excellent levelness was yield for $\mathrm{E}$. The color levelness of sample $\mathrm{E}$ was $54 \%$ more than sample A. Though, there was difference in average color difference value but all samples showed excellent color levelness. The continuing upturn of dyeing temperature boosts the fiber swelling to promote easier penetration of dye into interior of the fiber homogeneously which conceivably leads positive impact on color levelness [25].

\subsection{Color Strength (K/S) Value}

Figure 4 illustrates the effect of temperature variation on color strength of dyed samples.

The order of color strength value of samples were found $\mathrm{E}>\mathrm{F}>\mathrm{C}>\mathrm{A}>\mathrm{B}>\mathrm{D}$. The maximum color strength 0.65 is yield for $\mathrm{E}$ at wavelength $360 \mathrm{~nm}$. The $\mathrm{K} / \mathrm{S}$ value of $\mathrm{A}, \mathrm{B}, \mathrm{C}, \mathrm{D}$ and $\mathrm{F}$ samples were $10.77 \%, 15.38 \%, 9.23 \%, 23.08 \%$ and $6.15 \%$ lower than E. For successive increase in temperature the rate of diffusion of dye molecules in the bulk of dye bath increase the gradient of dye adsorption rate on fibre surface i.e. pseudo-second order rate constant [24,25] remarkably which bolster the fashion of yielded K/S values. Thermal degradation [27] may be a probable reason of lower $\mathrm{K} / \mathrm{S}$ value at $110^{\circ} \mathrm{C}$.

Table 4. Effect of temperature variations on color levelness value

\begin{tabular}{|c|c|c|c|c|c|c|c|c|c|c|c|}
\hline \multirow{3}{*}{$\begin{array}{c}\text { Samples } \\
\text { Types }\end{array}$} & \multicolumn{10}{|c|}{$\Delta \mathbf{E}$ values of dyed samples } & \multirow{3}{*}{$\begin{array}{c}\text { Average } \\
\Delta \mathbf{E}\end{array}$} \\
\hline & \multirow{2}{*}{$\mathrm{R}-1$} & $\mathrm{R}-2$ & $\mathrm{R}-3$ & R-4 & $\mathrm{R}-5$ & $\mathrm{R}-6$ & $\mathrm{R}-7$ & R-8 & R-9 & R-10 & \\
\hline & & \multicolumn{9}{|c|}{ Batch readings } & \\
\hline A & \multirow{5}{*}{ Standard } & 0.587 & 0.116 & 0.105 & 0.221 & 0.071 & 0.077 & 0.056 & 0.073 & 0.048 & 0.150 \\
\hline B & & 0.185 & 0.226 & 0.332 & 0.056 & 0.120 & 0.012 & 0.134 & 0.081 & 0.053 & 0.133 \\
\hline $\mathrm{C}$ & & 0.029 & 0.178 & 0.277 & 0.067 & 0.078 & 0.049 & 0.120 & 0.111 & 0.014 & 0.103 \\
\hline $\mathrm{E}$ & & 0.292 & 0.038 & 0.067 & 0.029 & 0.072 & 0.047 & 0.048 & 0.017 & 0.014 & 0.069 \\
\hline $\mathrm{F}$ & & 0.303 & 0.124 & 0.157 & 0.023 & 0.087 & 0.055 & 0.142 & 0.096 & 0.037 & 0.114 \\
\hline
\end{tabular}

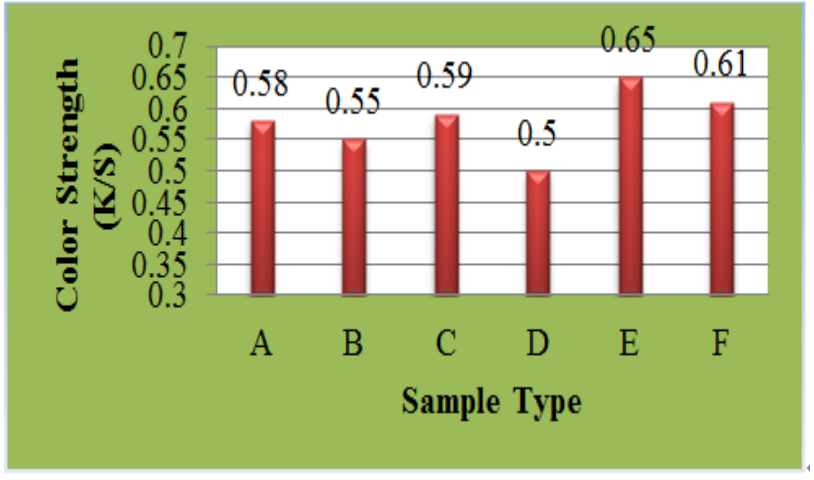

Figure 4. Color strength $(\mathrm{K} / \mathrm{S})$ value

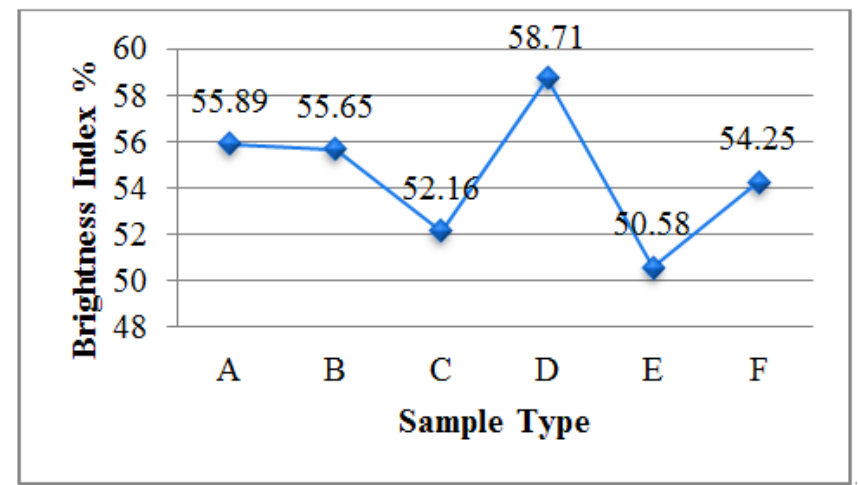

Figure 5. Brightness index $\%$ value 
Table 5. Color fastness to wash

\begin{tabular}{|c|c|c|c|c|c|c|c|}
\hline \multirow{2}{*}{$\begin{array}{c}\text { Samples } \\
\text { types }\end{array}$} & \multirow{2}{*}{ Change in Color } & \multicolumn{9}{|c|}{ Staining in Color } & \multicolumn{7}{c|}{ Acrylic } & Wool \\
\cline { 3 - 9 } & & Acetate & Cotton & Nylon & Polyester & $4-5$ & $3-4$ \\
\hline A & 4 & $4-5$ & 4 & $4-5$ & $4-5$ & $4-5$ & $3-4$ \\
\hline B & 4 & $4-5$ & 4 & $4-5$ & $4-5$ & $4-5$ & 4 \\
\hline C & $4-5$ & $4-5$ & 4 & $4-5$ & $4-5$ & $4-5$ & $4-5$ \\
\hline D & $4-5$ & $4-5$ & $4-5$ & $4-5$ & 4 & $4-5$ & $4-5$ \\
\hline E & $4-5$ & $4-5$ & $4-5$ & $4-5$ & $4-5$ & $4-5$ & 4 \\
\hline F & 4 & $4-5$ & 4 & $4-5$ & 4 & & 4 \\
\hline
\end{tabular}

\subsection{Brightness Index Value}

Regarding brightness index value, the samples orders were found as $\mathrm{D}>\mathrm{A}>\mathrm{B}>\mathrm{F}>\mathrm{C}>\mathrm{E}$ (Figure 5). Temperature variation has positive and negative impact on brightness index value. The highest brightness index value was obtained 58.71 for D and lowest value 50.58 for E. The brightness index value of the samples $\mathrm{A}, \mathrm{B}, \mathrm{C}$ and $\mathrm{F}$ showed $10.5 \%, 10 \%, 3.12 \%$ and $7.26 \%$ more than E. The molecular structure of dye and fiber becomes open for proliferation of temperature which facilitates the dye adsorption rate [26] and hence the lower brightness index i.e. darkest shade was obtained at $100^{\circ} \mathrm{C}(\mathrm{E})$.

\subsection{Color Fastness to Wash}

Table 5 presented the color fastness to wash. The overall results of color fastness to wash of samples were very good to excellent. A, B and F were showed very good result in color change. Slightly color staining [8] has occurred on cotton and wool for the sample A, B, C and F. All other samples exhibited excellent grade in color change and staining.

\subsection{Color Fastness to Rubbing and Light}

The grade of color fastness to rubbing and light of the samples were evaluated and presented in the Table 6. The overall results of color fastness to rubbing of samples are good to excellent. Wet rubbing properties are lower than dry rubbing. A, B, C, D and F exhibited good wet rubbing and excellent dry properties. Only E showed excellent rubbing properties in both cases.
Table 6. Color fastness to rubbing and light fastness properties.

\begin{tabular}{|c|c|c|c|}
\hline \multirow{2}{*}{$\begin{array}{c}\text { Samples } \\
\text { types }\end{array}$} & \multicolumn{2}{|c|}{ Rubbing fastness } & \multirow{2}{*}{ Light fastness } \\
\cline { 2 - 3 } & Dry rubbing & Wet rubbing & \\
\hline A & $4-5$ & 4 & 2 \\
\hline B & $4-5$ & $3-4$ & 2 \\
\hline C & $4-5$ & $3-4$ & $2-3$ \\
\hline D & $4-5$ & 4 & $2-3$ \\
\hline E & $4-5$ & $4-5$ & $2-3$ \\
\hline F & $4-5$ & $3-4$ & 2 \\
\hline
\end{tabular}

Unfortunately, the samples A, B and F showed poor light fastness properties i.e. 2 where $\mathrm{C}, \mathrm{D}$ and $\mathrm{E}$ showed a little bit improved grade i.e. 2-3 which was harmonious with previous experiment of cotton coloration using banana leaves [8]. Poor light fastness correspond both lower photo stability of natural pigments and weaker dye-fiber interaction [29].

\subsection{Color Fastness to Water}

Table 7 illustrates the grading of color fastness to water. The overall results of all samples were showed very good to excellent. A, B and C showed color change. A, B, C and F were exhibited staining in color onto cotton, wool and polyester slightly. Excellent grade both color staining and color change exhibited for all other samples. More staining observed onto wool in case of A. For upturning temperature after $100^{\circ} \mathrm{C}$ reduces the dye-fiber interaction due to thermal instability of natural pigments [27].

Table 7. Color fastness to water

\begin{tabular}{|c|c|c|c|c|c|c|c|}
\hline \multirow{2}{*}{ Samples types } & \multirow{2}{*}{$\begin{array}{c}\text { Change in } \\
\text { Color }\end{array}$} & \multicolumn{5}{|c|}{ Staining in Color } \\
\cline { 3 - 8 } & & Acetate & Cotton & Nylon & Polyester & \multirow{2}{*}{ Acrylic } & \multirow{2}{*}{ Wool } \\
\hline A & 4 & $4-5$ & 4 & $4-5$ & $4-5$ & $4-5$ & $3-4$ \\
\hline B & $3-4$ & $4-5$ & 4 & $4-5$ & $4-5$ & $4-5$ & 4 \\
\hline C & 4 & $4-5$ & 4 & $4-5$ & 4 & $4-5$ & 4 \\
\hline D & $4-5$ & $4-5$ & $4-5$ & $4-5$ & $4-5$ & $4-5$ & $4-5$ \\
\hline E & $4-5$ & $4-5$ & $4-5$ & $4-5$ & $4-5$ & $4-5$ & $4-5$ \\
\hline F & $4-5$ & $4-5$ & $4-5$ & $4-5$ & 4 & $4-5$ & 4 \\
\hline
\end{tabular}




\subsection{Color Fastness to Perspiration}

Table 8 illustrates the evaluation of fastness to perspiration. The overall results of color fastness to perspiration of samples in both alkaline and acidic medium were very good to excellent. Slightly color change and color staining has occurred for both acid and alkaline perspiration [8].

Table 8. Color fastness to perspiration

\begin{tabular}{|c|c|c|c|c|}
\hline \multirow{2}{*}{$\begin{array}{c}\text { Samples } \\
\text { types }\end{array}$} & \multicolumn{2}{|c|}{ Alkaline } & \multicolumn{2}{c|}{ Acid } \\
\cline { 2 - 5 } & $\begin{array}{c}\text { Change in } \\
\text { Color }\end{array}$ & $\begin{array}{c}\text { Color } \\
\text { Staining on } \\
\text { Cotton }\end{array}$ & $\begin{array}{c}\text { Change in } \\
\text { color }\end{array}$ & $\begin{array}{c}\text { Color } \\
\text { Staining on } \\
\text { Cotton }\end{array}$ \\
\hline A & $3-4$ & 4 & $3-4$ & 4 \\
\hline B & $4-5$ & $4-5$ & $4-5$ & $4-5$ \\
\hline C & 4 & 4 & $4-5$ & $4-5$ \\
\hline D & $4-5$ & $4-5$ & $4-5$ & $4-5$ \\
\hline E & $4-5$ & $4-5$ & $4-5$ & $4-5$ \\
\hline F & 4 & 4 & 4 & 4 \\
\hline
\end{tabular}

Expediently, others samples showed excellent grade i.e. 4-5.

With increment of temperature, specimens showed a slight improvement in overall color fastness properties. For raising temperature it is evident that, the stronger dye-fiber bond due to higher rate of diffusion of dye molecules, the easier is the transfer of the excitation energy from the dye molecule to the fiber macromolecular chain. Moreover, higher temperature leads swelling of cellulose fibers. Thus, the dye fiber linkage assists as a bridge for conveying the excitation energy between the two components of the dye fiber ambient coordination. So, color fastness upturns at higher temperature for stronger dye-fiber interaction [8]. But color durability properties downturns after raising temperature than $100^{\circ} \mathrm{C}$ for thermal instability of natural dye molecule [27].

\section{Conclusions}

This study is a new methodology for textile coloration using green chemistry by banana bio-resources waste. Cotton knitted fabric dyed with banana floral stem sap delivered light shade. Marginally profound shade was created with expanding dyeing temperature. However, color obsession rate raise with the expanding of dyeing temperature up to $100^{\circ} \mathrm{C}$ and starts wane at $110^{\circ} \mathrm{C}$. From all colorimetric and color fastness properties it is presumed that the best result was acquired at $100^{\circ} \mathrm{C}$. So, the optimal dyeing temperature is $100^{\circ} \mathrm{C}$ for cotton coloration with banana floral stem sap. The natural dyed showed analogous properties of synthetic dye although no chemical were used in whole process. This coloration process by banana floral stem sap can be utilized where light fastness is not so essential. Further study can be done to enhance its light fastness and producing dark shade.

\section{REFERENCES}

[1] Sen S, Demirer GN. "Anaerobic treatment of real textile wastewater with a fluidized bed reactor". Water Research, Vol. 37, No.8, pp1868-1878, 2003.

[2] Melih Günay. "Eco-Friendly Textile Dyeing and Finishing". In Tech, 2013.

[3] Bhuiyan M. R., Rahman, M.M. Shaid A. and Khan M.A., "Application of gamma irradiated textile wastewater for the pretreatment of cotton fabric". Environment and Ecology Research, vol.2 No.3, pp.149-152, 2014.

[4] Ali S., Nisar N. \& Hussain T., "Dyeing properties of natural dyes extracted from eucalyptus". The Journal of the Textile Institute; Vol. 98, No. 6, pp 559-562, 2007.

[5] Richards Blackburn, "Natural Polysaccharides and Their Interactions with Dye Molecules: Applications in Effluent Treatment". Environmental Science \& Technology, Vol. 38; No.18, pp 4905-4909, 2004.

[6] Sasmita Baliarsingh, Jyotsna rani Jena, Trupti Das, Nalin B. Das, "Role of cationic and anionic surfactants in textile dyeing with natural dyes extracted from waste plant materials and their potential antimicrobial properties". Industrial Crops and Products, Vol. 50, pp 618-624, 2013.

[7] Samanta, A. K., Agarwal, P. "Application of natural dyes on textiles". Indian Journal of Fibre and Textile Research, Vol.34, pp 384-399, 2009.

[8] Salah. M. Saleh, Yasser A. Abd-El-Hady, Kh. El-Badry. "Eco-friendly Dyeing of Cotton Fabric with Natural Colorants Extracted from Banana Leaves". International Journal of Textile Science, Vol. 2; No. 2 pp 21-25, 2013.

[9] Debabandya Mohapatra, Sabyasachi Mishra and NamrataSutar, "Banana and its by-product utilization: An overview". Journal of Scientific and Industrial Research, Vol. 69, pp 323-339, 2010.

[10] Kumar Sampath K. P., Bhowmik Debjit, Duraivel S., Umadevi M., "Traditional and Medicinal Uses of Banana". Journal of Pharmacognosy and Phytochemistry; Vol 1; No. 3; pp. 51-63, 2012.

[11] Dzomeku B. M. and Boateng O. K., "Exploring the Potential of Banana Sap as Dye for the Adinkra industry in Ghana". International Journal of Bio-resource and Stress Management; Vol. 4, No.2, pp. 378-381, 2013.

[12] Paul V., Kanny K., Redhi G.G., "Formulation of a novel bio-resin from banana sap". Industrial Crops and Products; Vol 43; pp. 496- 505, 2013.

[13] Samanta, A.K., Agarwal, P. "Application of natural dyes on textiles”. Indian J. Fibre Text. Res.; Vol. 34; pp. 384-399, 2009.

[14] Shuaibing, Z.M.Z.S.L. and Qihua, Z., “Adsorption of dye wastewater by banana peel powder immobilized by sodium alginate". Chinese Journal of Environmental Engineering, Vol.6, p.036, 2013.

[15] Millward S, "Color difference equations and their assessment”. Test Target J 9:19-26, 2009. 
[16] Mohammad Gias Uddin, "Extraction of eco-friendly natural dyes from mango leaves and their application on silk fabric". Textiles and Clothing Sustainability, Vol.1, No.7, 2015.

[17] Mcdonald, R (Ed.). (1997). Color physics for industry (2nd ed.). Soc. Bradford: Dyers and Colorist

[18] Paper and board: Measurement of diffused blue reflectance factor (ISO-brightness) ISO $2469 \& 2470$, 2nd (International Prganization for Standaradization Switzerland), 1977,1

[19] AATCC.2013. AATCC Test Method 61-2013 Colorfastness to Laundering: Accelerated

[20] AATCC. 2013. AATCC Test Method 8-2013 Colorfastness to Rubbing

[21] AATCC. 1996. AATCC Test Method 125-2013 Colorfastness to light

[22] AATCC. 2008. AATCC Test Method 107-2013 Colorfastness to Water

[23] AATCC. 2006. AATCC Test Method 15-2013 Colorfastness to Perspiration
[24] Shalini Chandravanshi, Santosh K. Upadhyay \& Abha Bhargava, "Effect of Ionic Surfactants on the Adsorption of Quercus infectoria Natural Dye on Cotton Fiber: A Kinetic Study". Journal of Dispersion Science and Technology, Vol.35, No.10, pp 1427-1433, 2014.

[25] Vickerstaff, Thomas. "Physical chemistry of Dyeing." 1954.

[26] Shahid, M. A., Hossain, M. I., Hossain, D., \& Ali, A.; "Effect of Different Dyeing Parameters on Color Strength \& Fastness Properties of Cotton-Elastane (CE) and Lyocell-Elastane (LE) Knit Fabric". International Journal of Textile Science, Vol. 5, No.1, pp.1-7, 2016.

[27] Ahn, C., Zeng, X., Li, L., \& Obendorf, S. K., "Thermal degradation of natural dyes and their analysis using HPLC-DAD-MS". Fashion and Textiles, Vol. 1, No.1, pp.1-13, 2014.

[28] Broadbent, A. D., Basic principles of textile coloration (Vol. 132). West Yorkshire: Society of Dyers and Colorists, 2001.

[29] Ali, S. Evaluation of cotton dyeing with aqueous extracts of natural dyes from indigenous plants ( $\mathrm{PhD}$ Thesis), Pakistan University of Agriculture, Faisalabad. (2007). 